\title{
Maternal and Perinatal Outcomes in Hypertensive Disorders of Pregnancy and Factors Influencing It: A Prospective Hospital-Based Study in Northeast India
}

\author{
Subrat Panda ${ }^{1}$, Rituparna Das ${ }^{1}$, Nalini Sharma ${ }^{2}$, Ananya Das ${ }^{1}$, Prakash Deb ${ }^{3}$, Kaushiki Singh ${ }^{1}$ \\ 1. Obstetrics and Gynaecology, North Eastern Indira Gandhi Regional Institute of Health \& Medical Sciences \\ (NEIGRIHMS), Shillong, IND 2. Obstetrics and Gynecology, North Eastern Indira Gandhi Regional Institute of Health \& \\ Medical Sciences (NEIGRIHMS), Shillong, IND 3. Anesthesiology and Critical Care, North Eastern Indira Gandhi \\ Regional Institute of Health \& Medical Sciences (NEIGRIHMS), Shillong, IND
}

Corresponding author: Rituparna Das, dasrituparna30@gmail.com

\begin{abstract}
Introduction

Hypertensive disorders frequently complicate pregnancy and contribute substantially to maternal and perinatal morbidity and mortality. Identification of risk factors for hypertensive disorders of pregnancy (HDP) can help determine the particular patient group which requires appropriate intervention.
\end{abstract}

\section{Methods}

This prospective cross-sectional hospital-based study conducted from January 2016 to January 2019 included all pregnant women beyond 20 weeks of gestation complicated by HDP. The objectives were to determine the incidence of HDP and associated maternal and perinatal mortality and morbidity rates along with factors influencing it. Data collected were entered in Microsoft Excel (Microsoft Corporation, Redmond, WA) and analyzed with the Statistical Package for the Social Sciences (SPSS) software version 21 (IBM Corp. Armonk, $\mathrm{NY})$.

\section{Results}

In our study, out of 5460 deliveries, 402 (7.4\%) cases had HDP, 27.6\% had gestational hypertension, 27.6\% had mild preeclampsia, 33.6\% had severe preeclampsia, and 11.2\% had eclampsia. Fifty-four (13.4\%) cases required admission in the intensive care unit and 12 (2.9\%) ended in maternal deaths. The cause of maternal mortality was cerebral hemorrhage in eight (66.6\%) cases and pulmonary edema in four (33.3\%) cases. All maternal deaths occurred in women with severe preeclampsia and eclampsia and eclampsia was significantly higher. Maternal deaths were more when systolic blood pressure (SBP) was $\geqslant 160 \mathrm{mmHg}$, diastolic blood pressure (DBP) was $\geqslant 110 \mathrm{mmHg}$, significantly more with $3+$ proteinuria, but no association was found with age, parity, booking status, socio-economic status, gestational age, or mode of delivery. All mothers with HDP received treatment with antihypertensives. There were 60 (14.9\%) cases of perinatal mortality.

Review began 02/10/2021 Review ended 03/15/2021 Published 03/18/2021

\section{() Copyright 2021}

Panda et al. This is an open access article distributed under the terms of the Creative Commons Attribution License CC-BY 4.0., which permits unrestricted use, distribution, and reproduction in any medium, provided the original author and source are credited.
Perinatal deaths were more in unbooked cases and preterm HDP, significantly more with SBP $\geqslant 160 \mathrm{mmHg}$, $\mathrm{DBP} \geqslant 110 \mathrm{mmHg}$ and $\geqslant 2+$ proteinuria, but no association was found with parity or mode of delivery. Besides mortality, there was a significant burden of maternal and perinatal morbidity, which was more in women with severe preeclampsia and eclampsia.

\section{Conclusion}

Routine antenatal screening for HDP in all pregnant women with appropriate and timely interventions in women at risk may help reduce HDP-related maternal and perinatal morbidity and mortality.

Categories: Obstetrics/Gynecology

Keywords: hypertensive disorders of pregnancy, preeclampsia, eclampsia, gestational hypertension, maternal mortality, perinatal outcome, proteinuria, antenatal screening

\section{Introduction}

Hypertensive disorders complicate $5 \%$ to $10 \%$ of all pregnancies and form a lethal trio with hemorrhage and infection [1]. A variation in maternal and perinatal morbidity and mortality has been observed worldwide, which could be the result of differences in the socio-economic background of nations as well as the quality of obstetric care delivered to these women. A confidential inquiry into maternal deaths in the UK found hypertensive disorders to be the second leading direct cause of maternal mortality [2]. In the USA, 7\% to 15\% of all pregnancies were affected by hypertensive disorders and were associated with up to $22 \%$ of all perinatal mortality and 30\% of all maternal mortality [3]. A study in India in 2006 reported the incidence of 
hypertensive disorders complicating pregnancy as 5.38\% with preeclampsia, eclampsia, and HELLP (hemolysis, elevated liver enzymes, and low platelet count) syndrome accounting for $44 \%, 40 \%$, and $7 \%$ of cases, respectively [4]. Maternal and perinatal deaths have been reported to be $5.5 \%$ and $37.5 \%$, respectively [4]. Maternal mortality in women with eclampsia is very high in India, ranging from $8 \%-14 \%$ [5]. With proper antenatal care, early recognition of preeclampsia, and timely intervention, the development of eclampsia and its associated complications can be prevented. However, in few patients where eclampsia develops without any preceding features of preeclampsia, the proper management of eclampsia rather than its prevention is vital in improving maternal and fetal outcomes. Though maternal mortality is decreased in developed countries, it is still high in developing countries and is mainly related to eclampsia, accidental hemorrhage, pulmonary edema, disseminated intravascular coagulation, acute renal failure, and HELLP syndrome [6]. Perinatal mortality, however, continues to be high even in developed countries and is reported to be up to $20 \%$ in the developing countries, half of which are stillborn [6]. This study was conducted in our institute to determine the incidence of hypertensive disorders of pregnancy and associated maternal and perinatal mortality and morbidity rates, along with the factors influencing it.

\section{Materials And Methods}

This was a prospective, cross-sectional, hospital-based study conducted on women with pregnancies complicated by hypertensive disorders in a teaching hospital in northeast India from January 2016 to January 2019. The criteria for defining different types of hypertension were:

- Preeclampsia was diagnosed in women with a blood pressure of 140/90 $\mathrm{mmHg}$ or above on two occasions at least four hours apart after 20 weeks of gestation with proteinuria or in those without proteinuria by the presence of thrombocytopenia (less than 100,000/microlitre), impaired liver function (serum liver transaminases to twice the normal level), new-onset renal insufficiency (serum creatinine more than 1.1 $\mathrm{mg} / \mathrm{dL}$ or doubling of serum creatinine without any other renal pathology), presence of pulmonary edema, or new-onset visual disturbances or cerebral symptoms. Severe preeclampsia was diagnosed where the blood pressure was 160/110 $\mathrm{mmHg}$ and above besides thrombocytopenia, progressive renal dysfunction, impaired liver function, pulmonary edema, and new-onset cerebral or visual disturbances, as already described, with the presence of severe and persistent right upper quadrant or epigastric pain not responsive to medication and other causes excluded. The rest were classified as having mild preeclampsia.

- Eclampsia was diagnosed where a seizure developed in women with hypertension, which was not attributed to any other cause.

- Gestational hypertension was diagnosed in women with hypertension beyond 20 weeks of gestation in the absence of proteinuria or the systemic findings of preeclampsia.

- Chronic hypertension was diagnosed in women with hypertension prior to pregnancy or prior to 20 weeks of gestation.

The presence of proteinuria was detected using a dipstick and classified into $1+/ 2+/ 3+$. The diagnosis of HELLP syndrome was based on the presence of hemolysis with increased serum lactate dehydrogenase level $(>600 \mathrm{U} / \mathrm{L})$, serum aspartate transaminase $(\geqslant 70 \mathrm{U} / \mathrm{L})$, and platelet count $<100 \times 109 / \mathrm{L}$ according to the Tennessee Classification System.

All pregnant women beyond 20 weeks of gestation complicated by hypertensive disorders of pregnancy (HDP), both booked and un-booked, and admitted to our institute were included in the study. Pregnancies with chronic hypertension, associated medical complications like anemia, diabetes, vascular or renal disease, multiple pregnancies, fetal growth restriction (FGR) in a previous pregnancy, and a previous history of convulsions secondary to other medical causes were excluded from the study. Women from all socioeconomic classes were selected irrespective of their parity and consanguinity. A detailed history of present and previous pregnancies, including last menstrual period, expected date of delivery, and period of gestation were recorded in the proforma.

Prompt treatment was initiated in all women. Women with hypertension received antihypertensive therapy and all women with severe preeclampsia and eclampsia were administered magnesium sulfate according to the Pritchard regimen. All other clinical management, such as decisions regarding induction of labor, mode of delivery, fetal monitoring, etc., was done as per departmental protocol and standard operating procedure.

The primary objective of our study was to determine the incidence of hypertensive disorders in the northeastern pregnant population. The secondary objectives were to evaluate the maternal and perinatal mortality rates along with the factors influencing them. The association of adverse maternal and perinatal outcomes with the type of hypertensive disorder, degree of hypertension, degree of proteinuria, booking status of the women, gestational age, mode of delivery, and demographic variables like age, parity, and socioeconomic status were studied. Data collected were entered in Microsoft Excel (Microsoft Corporation, Redmond, WA) and analyzed with the Statistical Package for the Social Sciences (SPSS) software version 21 (IBM Corp. Armonk, NY). The chi-square test was used to compare the categorical variables. Based on 


\section{Cureus}

relative risk calculation, a p-value of less than 0.007 was considered statistically significant.

\section{Results}

In our study, 5460 deliveries were conducted in the study period; of which, 402 (7.4\%) cases had HDP. Twenty-seven point six (27.6\%) of them had gestational hypertension, $27.6 \%$ had mild preeclampsia, $33.6 \%$ had severe preeclampsia, $11.2 \%$ had eclampsia, and 12 (2.9\%) ended in maternal deaths. The cause of maternal mortality was cerebral hemorrhage and pulmonary edema with mortality due to cerebral hemorrhage being significantly higher (p-value 0.0013). All the maternal deaths occurred in women with severe preeclampsia and eclampsia. Maternal death in women with eclampsia was significantly higher than those with severe preeclampsia ( $\mathrm{p}$-value 0.0008 ). Also, maternal deaths were more in women with systolic blood pressure (SBP) $\geqslant 160 \mathrm{mmHg}$ and diastolic blood pressure (DBP) $\geqslant 110 \mathrm{mmHg}$ than in those with lower blood pressure, but the difference was not statistically significant. Maternal death was also significantly higher in women with $3+$ proteinuria (p-value 0.0013 ). There was, however, no significant association of age, parity, socioeconomic status, mode of delivery, or the booking status of the women with maternal mortality ( $\mathrm{p}$-value non-significant). Term or preterm development of hypertensive disorder had no significant association with maternal death ( $p$-value 0.6827). All mothers with HDP received treatment with antihypertensives. In our study, $1.9 \%$ cases had HELLP syndrome, 3.7\% cases had pulmonary edema, 3.9\% cases had a cerebral hemorrhage, $0.7 \%$ cases had acute renal failure (ARF), $7.5 \%$ cases had abruption placenta, and 5.7\% cases had postpartum hemorrhage (PPH). Fifty-four (54; 13.4\%) cases required intensive care unit (ICU) admission. All the mothers who had complications requiring ICU care had either severe preeclampsia or eclampsia. ICU admission was significantly more in women with eclampsia than severe preeclampsia (p-value 0.0004 ) (Table 1 ). Twelve $(12 ; 22.2 \%)$ of those shifted to the ICU ended in maternal mortality.

\begin{tabular}{|c|c|c|c|c|c|c|c|c|c|}
\hline Type of HDP & $\begin{array}{l}\text { No. of } \\
\text { cases }\end{array}$ & $\begin{array}{l}\% \text { of } \\
\text { cases }\end{array}$ & $\begin{array}{l}\text { HELLP } \\
\text { N (\%) }\end{array}$ & $\begin{array}{l}\text { Pulmonary } \\
\text { edema N (\%) }\end{array}$ & $\begin{array}{l}\text { Cerebral } \\
\text { hemorrhage N (\%) }\end{array}$ & $\begin{array}{l}\text { ARF } \\
N(\%)\end{array}$ & $\begin{array}{l}\text { Abruptio } \\
\text { placentae N (\%) }\end{array}$ & $\begin{array}{l}\text { PPH N } \\
\text { (\%) }\end{array}$ & $\begin{array}{l}\text { ICU } \\
\text { admission N } \\
(\%)\end{array}$ \\
\hline $\begin{array}{l}\text { Gestational } \\
\text { hypertension }\end{array}$ & 111 & 27.6 & & & & & & $\begin{array}{l}2 \\
(1.8 \%)\end{array}$ & \\
\hline $\begin{array}{l}\text { Mild } \\
\text { preeclampsia }\end{array}$ & 111 & 27.6 & & & & & 7 (6.3\%) & $\begin{array}{l}6 \\
(5.4 \%)\end{array}$ & \\
\hline $\begin{array}{l}\text { Severe } \\
\text { preeclampsia }\end{array}$ & 135 & 33.6 & $8(5.9 \%)$ & $8(5.9 \%)$ & $8(5.9 \%)$ & $\begin{array}{l}2 \\
(1.5 \%)\end{array}$ & $18(13.3 \%)$ & $\begin{array}{l}12 \\
(8.9 \%)\end{array}$ & 32 (23.7\%) \\
\hline Eclampsia & 45 & 11.2 & & 7 (15.6\%) & 8 (17.8\%) & $\begin{array}{l}1 \\
(2.2 \%)\end{array}$ & 5 (11.1\%) & $\begin{array}{l}3 \\
(6.7 \%)\end{array}$ & 22 (48.9\%) \\
\hline Total & 402 & $7.4 \%$ & $8(1.9 \%)$ & 15 (3.7\%) & 16 (3.9\%) & $\begin{array}{l}3 \\
(0.7 \%)\end{array}$ & 30 (7.5\%) & $\begin{array}{l}23 \\
(5.7 \%)\end{array}$ & 54 (13.4\%) \\
\hline
\end{tabular}

\section{TABLE 1: Maternal complications}

HELLP: hemolysis, elevated liver enzymes, and low platelet count; ARF: acute renal failure; PPH: postpartum hemorrhage; ICU: intensive care unit

There were 60 (14.9\%) cases of perinatal mortality. Perinatal mortality was significantly higher in women with eclampsia and severe preeclampsia ( $\mathrm{p}$-value $<0.0001$ ) and more so in eclampsia than in severe preeclampsia ( $p$-value $<0.0001$ ). Women with SBP $\geqslant 160 \mathrm{mmHg}$ and DBP $\geqslant 110 \mathrm{mmHg}$ had more perinatal deaths as compared to those with lower blood pressure ( $\mathrm{p}$-value 0.0011 and 0.0003 , respectively). Perinatal mortality was statistically higher in women with increasing proteinuria (p-value $<0.0001$ ) with $2+$ or $3+$ proteinuria having significantly more perinatal deaths as compared to trace or $1+$ proteinuria ( $\mathrm{p}$-value 0.0011). Perinatal mortality was significantly higher in young as well as elderly mothers ( $p$-value 0.0001$)$. Also, unbooked cases and women with preterm HDP had more perinatal deaths though not statistically significant (p-value 0.0113 and 0.0327 , respectively). Parity, socio-economic status, and mode of delivery had no significant association with perinatal death (p-value $0.2408,0.441$, and 0.2278 , respectively). See Table 2. One-hundred fifty-six (156; 38.8\%) babies delivered were healthy at birth, 102 (25.3\%) had preterm births with respiratory distress syndrome (RDS), 33 (8.2\%) had preterm births and FGR, 27 (6.7\%) had preterm births and hypoxia, three (0.74\%) had term births with FGR, 15 (3.7\%) had term births with FGR and hypoxia, six (1.5\%) had term births with FGR and meconium aspiration syndrome (MAS), 33 (8.2\%) had intrauterine fetal demise (IUFD), and 27 (6.7\%) had neonatal deaths. See Table 3. 


\section{Cureus}

\begin{tabular}{|c|c|c|c|c|c|}
\hline Factors & & $\begin{array}{l}\text { Maternal mortality } \\
\mathrm{N}(\%)\end{array}$ & $\begin{array}{l}\mathrm{P}- \\
\text { value }\end{array}$ & $\begin{array}{l}\text { Perinatal mortality N } \\
\text { (\%) }\end{array}$ & P-value \\
\hline \multirow{2}{*}{ Cause } & Pulmonary edema & $4(26.6 \%)$ & \multirow{2}{*}{0.0013} & & \\
\hline & $\begin{array}{l}\text { Cerebral } \\
\text { hemorrhage }\end{array}$ & $8(50 \%)$ & & & \\
\hline \multirow{3}{*}{ Type of HDP } & $\begin{array}{l}\text { Mild preeclampsia } \\
\text { (111) }\end{array}$ & 0 & \multirow{3}{*}{0.0008} & $3(2.7 \%)$ & \multirow{3}{*}{$\begin{array}{l}<0.0001 \text { [ }<0.0001 \text { (between severe } \\
\text { preeclampsia \& eclampsia)] }\end{array}$} \\
\hline & $\begin{array}{l}\text { Severe } \\
\text { preeclampsia (135) }\end{array}$ & $4(2.9 \%)$ & & 33 (24.4\%) & \\
\hline & Eclampsia (45) & $8(17.7 \%)$ & & $24(53.3 \%)$ & \\
\hline \multirow{2}{*}{ SBP (in mmHg) } & $\geq 160$ (150) & $11(7.3 \%)$ & \multirow{2}{*}{0.0649} & $39(26 \%)$ & \multirow{2}{*}{0.0011} \\
\hline & $<160$ (252) & $1(0.03 \%)$ & & $21(8.3 \%)$ & \\
\hline \multirow{2}{*}{ DBP (in mmHg) } & $\geq 110$ (120) & $10(8.3 \%)$ & \multirow{2}{*}{0.0349} & $36(30 \%)$ & \multirow{2}{*}{0.0003} \\
\hline & $<110$ (282) & $2(0.7 \%)$ & & 24 (8.5\%) & \\
\hline \multirow{3}{*}{ Proteinuria } & Trace /+1(111) & 0 & \multirow{3}{*}{0.0013} & $9(8.1 \%)$ & \multirow{3}{*}{$\begin{array}{l}<0.0001[0.0011 \text { (between trace } / 1+\text { and } 2+/ 3+ \\
\text { proteinuria)] }\end{array}$} \\
\hline & +2 (114) & $1(0.8 \%)$ & & $\begin{array}{l}21 \\
(18.4 \%)\end{array}$ & \\
\hline & +3 (84) & $11(13 \%)$ & & $\begin{array}{l}30 \\
(35.7 \%)\end{array}$ & \\
\hline \multirow{2}{*}{ Parity } & Primigravida (225) & $6(2.6 . \%)$ & \multirow{2}{*}{1.0} & 27 (12\%) & \multirow{2}{*}{0.2408} \\
\hline & Multipara (177) & 6 (3.3.\%) & & $33(18.6 \%)$ & \\
\hline \multirow{2}{*}{ Booking status } & Booked (237) & $1(0.4 \%)$ & \multirow{2}{*}{0.0649} & $22(9.2 \%)$ & \multirow{2}{*}{0.0113} \\
\hline & Unbooked (165) & 11 (6.6\%) & & $38(23 \%)$ & \\
\hline \multirow{3}{*}{$\begin{array}{l}\text { Socioeconomic } \\
\text { status }\end{array}$} & Low (180) & $7(3.8 \%)$ & \multirow{3}{*}{0.7378} & 32 (17.7\%) & \multirow{3}{*}{0.441} \\
\hline & Middle (172) & $4(2.3 \%)$ & & $22(12.7 \%)$ & \\
\hline & High (50) & $1(2 \%)$ & & $6(12 \%)$ & \\
\hline \multirow{3}{*}{ Age } & <25 (172) & $4(2.3 \%)$ & \multirow{3}{*}{0.296} & 39 (22.6\%) & \multirow{3}{*}{0.0001} \\
\hline & $25-35(160)$ & $4(2.5 \%)$ & & $7(4.3 \%)$ & \\
\hline & $>35(70)$ & $4(5.7 \%)$ & & $14(20 \%)$ & \\
\hline \multirow{2}{*}{ Mode of delivery } & Vaginal (212)) & $8(3.7 \%)$ & \multirow{2}{*}{0.6827} & $39(18.3 \%)$ & \multirow{2}{*}{0.2278} \\
\hline & Caesarean (190) & $4(2.1 \%)$ & & $21(11 \%)$ & \\
\hline \multirow{2}{*}{ Gestational age } & Preterm (162) & $6(3.7 \%)$ & \multirow{2}{*}{0.6827} & $36(22.2 \%)$ & \multirow{2}{*}{0.0327} \\
\hline & Term (240) & $6(2.5 \%)$ & & $24(10 \%)$ & \\
\hline
\end{tabular}

\section{TABLE 2: Maternal and perinatal mortality and associated factors}

HDP: hypertensive disorders of pregnancy; SBP: systolic blood pressure; DBP: diastolic blood pressure 


\section{Cureus}

\begin{tabular}{|c|c|c|c|c|c|}
\hline Perinatal outcome & $\begin{array}{l}\text { Gestational hypertension N } \\
\text { (\%) }\end{array}$ & $\begin{array}{l}\text { Mild preeclampsia N } \\
\text { (\%) }\end{array}$ & $\begin{array}{l}\text { Severe preeclampsia N } \\
\text { (\%) }\end{array}$ & $\begin{array}{l}\text { Eclampsia N } \\
\text { (\%) }\end{array}$ & $\begin{array}{l}\text { Total N } \\
\text { (\%) }\end{array}$ \\
\hline Healthy & $75(67.6 \%)$ & $60(54.1 \%)$ & $12(8.9 \%)$ & $9(20 \%)$ & $\begin{array}{l}156 \\
(38.8 \%)\end{array}$ \\
\hline Preterm births with RDS & $18(16.2 \%)$ & $30(27 \%)$ & $45(33.3 \%)$ & $9(20 \%)$ & $\begin{array}{l}102 \\
(25.3 \%)\end{array}$ \\
\hline Preterm births with FGR & $3(2.7 \%)$ & $9(8.1 \%)$ & $18(13.3 \%)$ & $3(6.7 \%)$ & $33(8.2 \%)$ \\
\hline Preterm births with hypoxic & $9(8.1 \%)$ & $6(5.4 \%)$ & $12(8.9 \%)$ & - & $27(6.7 \%)$ \\
\hline Term births with FGR & $3(2.7 \%)$ & - & - & - & $3(0.74 \%)$ \\
\hline $\begin{array}{l}\text { Term births with FGR and } \\
\text { hypoxia }\end{array}$ & $3(2.7 \%)$ & $3(2.7 \%)$ & $9(6.7 \%)$ & - & $15(3.7 \%)$ \\
\hline $\begin{array}{l}\text { Term births with FGR and } \\
\text { MAS }\end{array}$ & - & - & $6(4.4 \%)$ & - & $6(1.5 \%)$ \\
\hline IUFD & - & - & $18(13.3 \%)$ & $15(33.3 \%)$ & $33(8.2 \%)$ \\
\hline Neonatal death & & $3(2.7 \%)$ & $15(11.1 \%)$ & $9(20 \%)$ & $27(6.7 \%)$ \\
\hline
\end{tabular}

\section{TABLE 3: Perinatal outcome}

RDS: respiratory distress syndrome; FGR: fetal growth restriction; MAS: meconium aspiration syndrome; IUFD: intrauterine fetal demise

\section{Discussion}

In our study, the incidence of HDP was $7.3 \%$. Mehta et al. found an incidence of HDP of $6.9 \%$ in the Indian population [7]. Twenty-seven point six percent (27.6\%) cases in our study had gestational hypertension, another $27.6 \%$ cases had mild preeclampsia, $33.6 \%$ cases had severe preeclampsia, and $11.2 \%$ cases had eclampsia. Similar to our study, the study by Subki AH et al. reported the most prevalent hypertensive disorder as preeclampsia (54.9\%) followed by gestational hypertension (29.5\%) and then eclampsia (8.0\%) [8]. Regarding maternal complications, in our study, $1.9 \%$ cases had HELLP syndrome, $3.7 \%$ cases had pulmonary edema, 3.9\% cases had a cerebral hemorrhage, $0.7 \%$ cases had ARF, $7.4 \%$ cases had abruption placenta, and $5.7 \%$ cases had a postpartum hemorrhage. Most of the complications were seen in cases of severe preeclampsia and eclampsia. In the study by Seyom et al., 12.4\% of cases had HELLP syndrome, $7 \%$ had ARF, 2\% had abruption placentae, and 7\% had PPH [9]. We had 12 (2.9\%) maternal deaths. Bridwell et al., however, found $0.3 \%$ maternal mortality in women with HDP in their study [10]. In the present study, the cause of maternal mortality was pulmonary edema in four (33.3\%) cases and cerebral hemorrhage in eight (66.6\%) cases. In a study by Moodley, $50 \%$ of the maternal deaths were due to cerebral hemorrhage and $17.2 \%$ were due to pulmonary edema [11]. In our study, 16 (3.9\%) women had a cerebral hemorrhage, which is much higher than that reported in a study by Miller et al., where only $0.2 \%$ of women with preeclampsia developed pregnancy-associated stroke, and in another study by Wu and colleagues, where 0.08\% of HDP deliveries had a stroke [12-13]. All the women who had a cerebral hemorrhage in our study presented late to the hospital and the diagnosis of cerebral hemorrhage was made on admission and all had blood pressure (BP) $>160 / 110 \mathrm{mmHg}$. This reflects the poor healthcare-seeking behavior of the population. Also, since our institute is the only tertiary care center, it receives all the complicated cases of the state, which could be an additional reason for the higher incidence of cerebral hemorrhages in our study.

In our study, maternal mortality was significantly higher in women with eclampsia than with preeclampsia and in women with proteinuria of 3+. Maternal deaths were also higher, though not statistically significant, in unbooked cases and when SBP was $\geqslant 160 \mathrm{mmHg}$ and DBP $\geqslant 110 \mathrm{mmHg}$. All women who had maternal deaths were treated with antihypertensive. In the Control of Hypertension In Pregnancy Study (CHIPS) trial, severe hypertension ( $\geqslant 160 / 110 \mathrm{~mm} \mathrm{Hg}$ ), which is considered a stroke risk threshold, developed in $27.5 \%$ of women in the tight-control group and $40.6 \%$ of the women in the less-tight control group, and the difference was highly significant, both statistically as well as clinically [14]. The UK 'Confidential Enquiries into Maternal Deaths' has identified that the most serious fault in the care of women who died due to stroke was the failure to recognize the severity of and to treat the severe hypertension (particularly systolic) of preeclampsia $[2,15]$. In preeclampsia, the severity of proteinuria has been considered by some as a predictor for poor maternal outcome [16] but others refuted the association [17]. Unbooked patients (25.9\%) had more chances of developing HDP (25.9\%) as compared to booked ones (6.66\%) [18]. In our study, maternal mortality was more in women belonging to lower and middle-class economic status and in women more than 35 years of age. There was no association between maternal death and the mode of delivery. In our 
study, six maternal deaths were at a gestational age of less than 37 weeks and six deaths were at gestational age beyond that. Preeclampsia complicating pregnancy at or prior to 28 weeks are more likely to end in maternal mortality [19].

The prevalence of perinatal mortality in women with HDP has been found to be $25 \%$ in Ethiopia [20]. A study from Pakistan reported perinatal mortality of $17.5 \%$ [21]. A Norwegian study reported that $9.2 \%$ of all perinatal mortality was due to HDP [22]. In our study, the prevalence of perinatal mortality in HDP was $14.9 \%$. Perinatal mortality was significantly more when SBP $\geqslant 160 \mathrm{mmHg}$ and DBP $\geqslant 110 \mathrm{mmHg}$ (p-value $0.0011,0.0003$ respectively). The study by Endeshaw $\mathrm{G}$ et al. also found a statistically significant association of perinatal mortality with the highest systolic BP $\geqslant 160 \mathrm{mmHg}$ and diastolic BP $\geqslant 110 \mathrm{mmHg}$ [23]. Perinatal deaths were more in multigravida as compared to primigravida in our study (18.6\% vs $12 \%)$. Also, women with proteinuria of +2 and more had significantly higher perinatal deaths than with trace and +1 proteinuria (p-value 0.0011). However, in a study by Thangaratinam et al., proteinuria was considered a poor predictor of adverse fetal outcomes [17]. In our study, unbooked cases had higher perinatal mortality than booked cases though not statistically significantly (p-value 0.0113 ). In a Nigerian study too, the perinatal outcome was reported to be poorer in unbooked mothers as compared to booked mothers [24]. In our study, perinatal mortality was higher in young as well as elderly mothers. Socioeconomic condition and mode of delivery had no association with perinatal mortality. Women with preterm HDP had more perinatal mortality than term HDP though not statistically significantly (22.2\% versus $10 \%$, p-value 0.0327$)$. A study reported that nearly three-fourths of all perinatal deaths (71\%) in women with HDP occurred in those who delivered either preterm or very preterm [23]. In our study, neonatal morbidity was also more in women with severe preeclampsia, and most of the complications were related to preterm deliveries. The study by Isabela et al. also reported that neonates suffered mainly from preterm-related complications mostly in mothers with severe preeclampsia [25].

International Federation of Gynecology and Obstetrics (FIGO) screening criteria help diagnose women at risk of HDP using uterine artery Doppler and serum biomarkers in whom appropriate intervention can prevent the development of early-onset HDP [26]. In our study, the overall poor maternal and fetal outcome in HDP is more in women with severe preeclampsia and eclampsia.

\section{Conclusions}

Pregnancies complicated by hypertensive disorders contribute substantially to the burden of maternal and perinatal morbidity and mortality, which is more in women with eclampsia and severe preeclampsia as compared to gestational hypertension and mild preeclampsia. Both maternal and perinatal mortality was more in unbooked cases. A high incidence of cerebral hemorrhage with all presenting late reflects the poor healthcare-seeking behavior of the population. Identification of the risk factors for HDP would be useful for early diagnosis in the particular patient group that requires monitoring and appropriate intervention. Besides routine antenatal screening for HDP by blood pressure measurement, the assessment of urinary proteinuria should be conducted at every antenatal visit where resources are available.

\section{Additional Information}

\section{Disclosures}

Human subjects: Consent was obtained or waived by all participants in this study. Animal subjects: All authors have confirmed that this study did not involve animal subjects or tissue. Conflicts of interest: In compliance with the ICMJE uniform disclosure form, all authors declare the following: Payment/services info: All authors have declared that no financial support was received from any organization for the submitted work. Financial relationships: All authors have declared that they have no financial relationships at present or within the previous three years with any organizations that might have an interest in the submitted work. Other relationships: All authors have declared that there are no other relationships or activities that could appear to have influenced the submitted work.

\section{References}

1. Cunningham FG, Leveno KJ, Bloom SL: Hypertensive disorders. Williams Obstetrics. Cunningham FG (ed): McGraw-Hill, New York; 2018. 710-754.

2. Cantwell R, Clutton-Brock T, Cooper G, et al.: Saving mothers' lives: reviewing maternal deaths to make motherhood safer: 2006-2008. Brit J Obstet Gynecol. 2011, 118:1-203. 10.1111/j.1471-0528.2010.02847.x

3. Arias F, Daftary SN, Bhide AG, Arulkumaran S, Damania K: Hypertensive disorders in pregnancy. Practical Guide to High Risk Pregnancy and Delivery. A South Asian Perspective. Daftary SN (ed): Elsevier India, New Delhi; 2011. 397-439.

4. Prakash J, Pandey LK, Singh AK, Kar B: Hypertension in pregnancy: hospital based study . J Assoc Physicians India. 2006, 54:273-278.

5. Pal A, Bhattacharyya R, Adhikari S, Roy A, Chakrabarty D, Ghosh P, Banerjee C: Eclampsia-scenario in a hospital- a ten years study. Bangladesh Med Res Counc Bull. 2011, 37:66-70. 10.3329/bmrcb.v37i2.8437

6. Dutta DC: Hypertensive disorders in pregnancy. DC Dutta's Textbook of Obstetrics. Konar H (ed): Jaypee Brothers Medical Publishers (P) Ltd, New Delhi; 2015. 255-281.

7. Mehta B, Kumar V, Chawla S, Sachdeva S, Mahopatra D: Hypertension in pregnancy: a community-based study. Indian J Community Med. 2015, 40:273-278. 10.4103/0970-0218.164403 
8. Subki AH, Algethami MR, Baabdullah WM, Alnefaie MN, Alzanbagi MA, Alsolami RM, Abduljabbar HS: Prevalence, risk factors, and fetal and maternal outcomes of hypertensive disorders of pregnancy: a retrospective study in Western Saudi Arabia. Oman Med J. 2018, 33:409-415. 10.5001/omj.2018.75

9. Seyom E, Abera M, Tesfaye M, Fentahun N: Maternal and fetal outcome of pregnancy related hypertension in Mettu Karl Referral Hospital, Ethiopia. J Ovarian Res. 2015, 8:10. 10.1186/s13048-015-0135-5

10. Bridwell M, Handzel E, Hynes M, et al.: Hypertensive disorders in pregnancy and maternal and neonatal outcomes in Haiti: the importance of surveillance and data collection. BMC Pregnancy Childbirth. 2019, 19:208. 10.1186/s12884-019-2361-0

11. Moodley J: Maternal deaths due to hypertensive disorders in pregnancy: Saving Mothers report 2002-2004 . Cardiovasc J Afr. 2007, 18:358-361.

12. Miller EC, Gatollari HJ, Too G, et al.: Risk factors for pregnancy-associated stroke in women with preeclampsia. Stroke. 2017, 48:1752-1759. 10.1161/STROKEAHA.117.017374

13. Wu Pensée, Jordan KP, Chew-Graham CA, et al.: Temporal trends in pregnancy-associated stroke and its outcomes among women with hypertensive disorders of pregnancy. J Am Heart Assoc. 2020, 9:e016182. 10.1161/JAHA.120.016182

14. Magee LA, von Dadelszen P, Rey E, et al.: Less-tight versus tight control of hypertension in pregnancy . N Engl J Med. 2015, 372:407-417. 10.1056/nejmoa1404595

15. Saving mothers' lives: reviewing maternal deaths to make motherhood safer - 2003-2005. The 7th report of the confidential enquiries into maternal deaths in the United Kingdom. Confidential Enquiry into Maternal and Child Health, London. (2007).

https://elearning.rcog.org.uk//sites/default/files/Postpartum\%20sepsis/CEMACH_Saving_Mothers_Lives_Chap7.pdf.

16. von Dadelszen P, Magee LA, Devarakonda RM, et al.: The prediction of adverse maternal outcomes in preeclampsia [Article in French]. J Obstet Gynaecol Can. 2004, 26:871-879. 10.1016/s1701-2163(16)30137-2

17. Thangaratinam S, Coomarasamy A, O'Mahony F, Sharp S, Zamora J, Khan KS, Ismail KMK: Estimation of proteinuria as a predictor of complications of pre-eclampsia: a systematic review. BMC Med. 2009, 7:10. 10.1186/1741-7015-7-10

18. Shahanaz M, Sravya R, Mahesh NT: Study of maternal and perinatal outcome in booked versus unbooked pregnant women in a rural based medical college. Journal of Evidence Based Medicine and Healthcare. 2019, 6:873-877. 10.18410/jebmh/2019/184

19. Mackay AP, Berg CJ, Atrash HK: Pregnancy-related mortality from preeclampsia and eclampsia . Obstet Gynecol. 2001, 97:533-538. 10.1016/s0029-7844(00)01223-0

20. Mersha AG, Abegaz TM, Seid MA: Maternal and perinatal outcomes of hypertensive disorders of pregnancy in Ethiopia: systematic review and meta-analysis. BMC Pregnancy Childbirth. 2019, 19:458. 10.1186/s12884-019-2617-8

21. Hossain N, Shah N, Khan N, Khan NH: Maternal and perinatal outcome of hypertensive disorders of pregnancy at a tertiary care hospital. J Dow Univ Health Sci Karachi. 2011, 5:12-16.

22. Ahmad AS, Samuelsen SO: Hypertensive disorders in pregnancy and fetal death at different gestational lengths: a population study of 2121371 pregnancies. BJOG. 2012, 119:1521-1588. 10.1111/j.14710528.2012.03460.x

23. Endeshaw G, Berhan Y: Perinatal outcome in women with hypertensive disorders of pregnancy: a retrospective cohort study. Int Sch Res Notices. 2015, 2015:208043. 10.1155/2015/208043

24. Chigbu B, Onwere S, Kamanu CI, Aluka C, Okoro O, Adibe E: Pregnancy outcome in booked and unbooked mothers in South Eastern Nigeria. East Afr Med J. 2009, 86:267-271. 10.4314/eamj.v86i6.54136

25. Barbosa IR, Silva WB, Cerqueira GS, Novo FN, Almeida FA, Garcia Novo JLV: Maternal and fetal outcome in women with hypertensive disorders of pregnancy: the impact of prenatal care. Ther Adv Cardiovasc Dis. 2015, 9:140-146. 10.1177/1753944715597622

26. Poon LC, Shennan A, Hyett JA, et al.: The International Federation of Gynecology and Obstetrics (FIGO) initiative on pre-eclampsia: a pragmatic guide for first-trimester screening and prevention. Int J Gynaecol Obstet. 2019, 145:1-33. 10.1002/ijgo.12802 